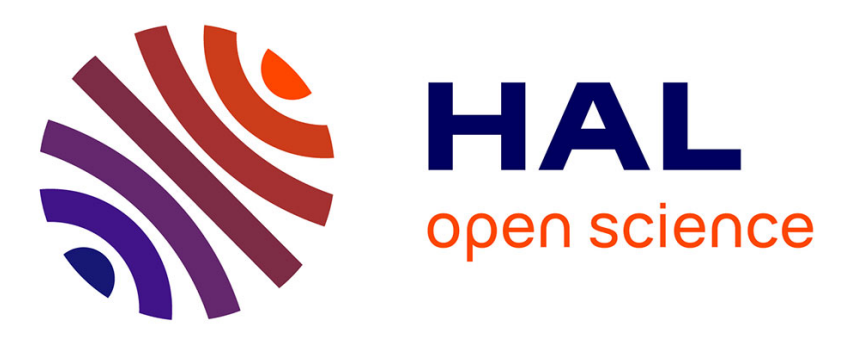

\title{
Why using High Frequency Dielectric Spectroscopy for biological analytics?
}

\author{
Mary Poupot, David Dubuc, François Artis, Katia Grenier, Jean-Jacques \\ Fournié
}

\section{- To cite this version:}

Mary Poupot, David Dubuc, François Artis, Katia Grenier, Jean-Jacques Fournié. Why using High Frequency Dielectric Spectroscopy for biological analytics?. IEEE Topical Conference on Biomedical Wireless Technologies, Networks, and Sensing Systems (BioWireleSS 2015 ), Jan 2015, San Diego, United States. 5p., 10.1109/BIOWIRELESS.2015.7152123 . hal-01951686

\author{
HAL Id: hal-01951686 \\ https://hal.laas.fr/hal-01951686
}

Submitted on 9 Dec 2019

HAL is a multi-disciplinary open access archive for the deposit and dissemination of scientific research documents, whether they are published or not. The documents may come from teaching and research institutions in France or abroad, or from public or private research centers.
L'archive ouverte pluridisciplinaire HAL, est destinée au dépôt et à la diffusion de documents scientifiques de niveau recherche, publiés ou non, émanant des établissements d'enseignement et de recherche français ou étrangers, des laboratoires publics ou privés. 


\title{
Why using High Frequency Dielectric Spectroscopy for biological analytics?
}

\author{
Mary Poupot ${ }^{1,2}$, David Dubuc ${ }^{2,3}$, François Artis ${ }^{1,2,3}$, Katia Grenier ${ }^{2,3}$, Jean-Jacques Fournié , $^{1,2}$ \\ ${ }^{1}$ CRCT UMR1037-ERL5294 CNRS, 2 Av. Hubert Curien, F-31037, France \\ ${ }^{2}$ Univ. Toulouse 3, F-31400 Toulouse, France \\ ${ }^{3}$ CNRS, LAAS, 7 Av. Du Colonel Roche, F-31400 Toulouse, France
}

\begin{abstract}
Heterogeneity of cancer patients increases difficulties to find the best treatment for each patient. To adapt the treatment, the solution would be to detect the patient response in culture dish, instead to wait several months the result of the treatment measured by the disease regression. This would allow testing several treatments with different doses for the best response. Classical analytical techniques such as flow cytometry, confocal microscopy, immunohistochemistry, western blot, gene expression profiling, proteomics or metabolomics are not usually used for this kind of tests because of the heaviness of their implementation. High Frequency Dielectric Spectroscopy (HFDS) could be the solution while this approach compared to others presents several advantages: miniaturizing, processing speed, small sample, no invasive preparations such as fixation, no labeling and possible real time measurement. This opens the door to the development of HFDS for non-invasive biological analysis.
\end{abstract}

\section{INTRODUCTION}

There are many types of cancers which require different treatments as surgery, chemotherapies, targeted treatments when possible, hormonotherapies, immunotherapies or combinations of these treatments to improve the efficacy. Moreover, the heterogeneity relative to the patient such as age, condition of the patient or stage of the disease, increases the difficulty to find the best treatment. Define the best treatment adapted to the patient is solely based on the response to the treatment. The response to a treatment is reflected by the disappearance of the tumor thanks to the death of cancer cells or to the stop of the over proliferation of cancer cells. However, the regression of the tumor is monitored over several months after the treatment. If the tumor has not regressed, a precious time is lost for the patient to apply another treatment. The solution would be to detect the response of the patient before the application of the treatment. For this, cancer cells sample obtained from the patient can be analyzed for their responses to a treatment applied in vitro, ie in a culture dish. The expected response is the death of the cancer cell or a cycle arrest to stop its uncontrolled proliferation. Thus, the comparison of the cell response with and without drug treatment can give the efficacy of the treatment. Actually, detection of the cell death or cycle arrest can be performed with several well known techniques used in biological research; however, these techniques cannot be used classically for this kind of medical tests for each patient because of the heaviness of the implementation of these techniques. This encourages the research of new bio-analytical method lighter, less invasive, rapid and miniaturizing. The large development of microtechnologies in term of microfluidic and high frequency, allows today to promote the microwaveanalyzing Microsystems for cellular and molecular investigations. First, we will overview in this paper the conventional techniques used in fundamental research but not for medical application such as flow cytometry, confocal microscopy, immunohistochemistry, western blot, gene expression profile, proteomic or metabolomics. Most of these techniques need sample preparations more or less destructuring for the cells and time consuming, staining with fluorescent antibodies, bioinformatics analyses, large sample and give sometimes indirect responses. In a second time, we will highlight the potentialities of the High Frequency Dielectric Spectroscopy (HFDS) for cellular detection performing without labeling, fixation or invasive preparations but with small sample and possibility of real time.

\section{CONVENTIONAL TECHNIQUES}

\section{A. Flow cytometry}

Flow cytometry (FC) is used to visualize cell morphology and molecules which can characterize a cell type, a cell state (dead or alive, activated or resting) and various cell responses or functionalities. This visualization is only possible with a labeling with specific fluorescent probes or antibodies coupled to fluorochromes, the FC analysis basing on the specific excitation by an appropriated laser.

For instance, figure 1 show the graph obtained by FC for living cells (left) and dead cells (right). Dead cells were visualized thanks to a staining with two fluorescent molecules, Annexin V and 7-AAD, which recognize specifically dead cells. Living cells corresponding to untreated cells were negative for the fluorescence, dots left of the vertical bar and below the horizontal bar. Dead cells interacting with fluorescent Annexin V and 7-AAD were represented by the dots right of the vertical bar and/or above the horizontal bar. Treatment of BV2 cells by CD38-siRNA induced death of some cells which became positive for the fluorescence corresponding to Annexin $\mathrm{V}$ 
and/or 7-AAD, some living cells staying negative for these markers [1].
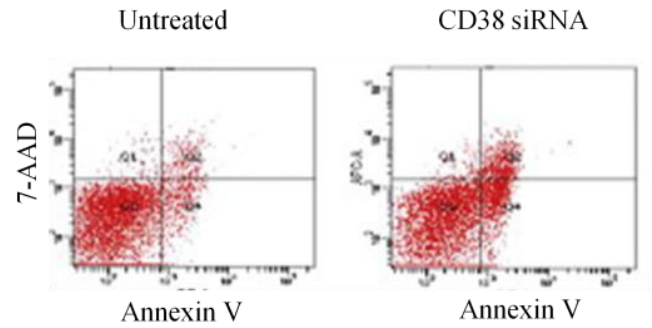

Fig. 1. Flow cytometry analysis of mouse microglial BV2 cells apoptosis treated or not for $24 \mathrm{~h}$ by CD38-siRNA $(33.3 \mathrm{nM})$.

\section{B. Confocal microscopy}

Compared to the conventional light microscope, the confocal approach in microscopy provides a slight increase in both lateral and axial resolution. The illumination in a confocal microscope is achieved by scanning one or more focused beams of light, usually from a laser, across the specimen. An image produced by scanning the specimen in this way is called an optical section. The major application of the laser scanning confocal microscopy in the biomedical sciences is for imaging either fixed or living tissues that have been labeled with one or more fluorescent probes. These fluorescent probes can be coupled to specific molecules targeting some specific membrane or intracellular molecules. This technique can be used to determine the cell apoptosis by the staining of the nucleus with Dapi (diamidino-2-phenylindole) which binds DNA. Chromatine condensation is one of the morphological hallmarks of apoptosis and the binding of Dapi on DNA allows the visualization of the nucleus morphology.

Treatment of leukemia cell line HL-60 by the proteinbound polysaccharide-K (PSK) for $72 \mathrm{~h}$ induces apoptosis of these cells, visualized by the DNA condensation with occurrence of small and condensed blue nuclei at $72 \mathrm{~h}$ (Figure 2) [2].
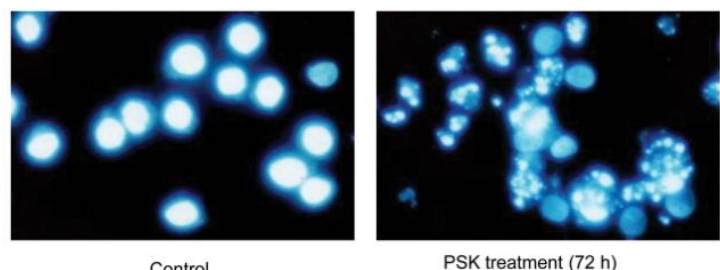

Fig. 2. Effect of PSK on chromatin condensation in HL-60 cells. DAPI stained cells observed under fluorescent microscopy after incubation $100 \mu \mathrm{g} / \mathrm{ml}$ PSK or buffer (control).

\section{Immunohistochemistry}

Immunohistochemistry or IHC refers to the process of detecting proteins in cells of a tissue section by exploiting the principle of specific antibodies binding. IHC staining is used for diagnosis of abnormal cells such as cancer cells. However, IHC is also used in basic research to understand the distribution and localization of biomarkers and the differentially expressed proteins in different parts of a biological tissue. Moreover, specific molecular markers are characteristic of particular cellular events such as apoptosis. In this case, some classical molecules are tested for their expression such as caspases, Bax, Bcl-2... We illustrate an IHC staining of apoptosis with the treatment by the alkaloid TARAP of hepatocellular carcinoma cells (HCC) for $24 \mathrm{~h}$ which increases the expression of the pro-apoptotic protein Bax in brown on the Figure 3.
Control

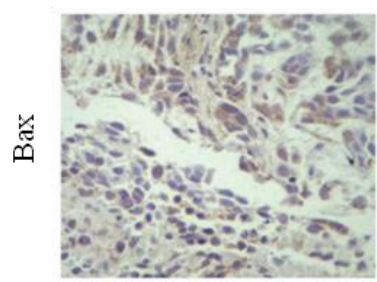

TARAP (72h)

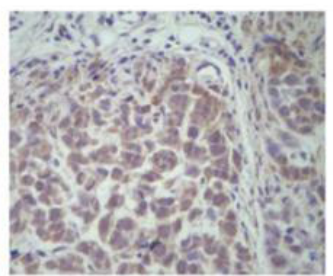

Fig. 3. Effect of TARAP on the Bax expression in HCC. Tumor tissues were processed for IHC staining for Bax in brown [3].

\section{Western blot}

Western blot is used to detect specific proteins in a sample of cells or tissue homogenate or extract. Native proteins are separated using gel electrophoresis according to the length of the polypeptide. The proteins are then transferred to a membrane (typically nitrocellulose or PVDF), where they ar stained with specific antibodies targeting proteins [4].

In figure 4 is represented a western blot of extract from epithelial cells treated or not with $\mathrm{H}_{2} \mathrm{O}_{2}$ at different time. $\mathrm{H}_{2} \mathrm{O}_{2}$ is known to induce apoptosis by an oxidative stress leading to the expression of two molecules: caspase-3 (17 $\mathrm{kDa})$ and caspase-9 (35 kDa).

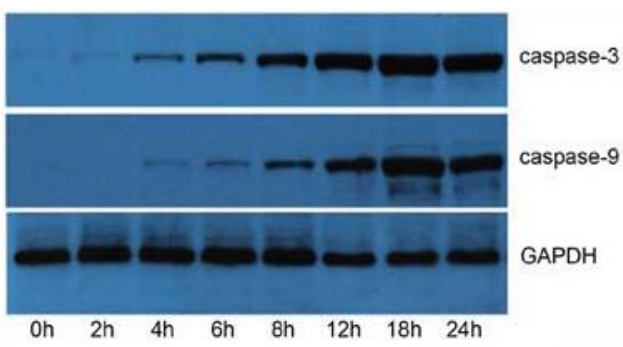

Fig. 4. Western Blot at 2, 4, 6, 8, 12, 18 and 24h of epithelial cells treated by $50 \mu \mathrm{M} \mathrm{H} 2 \mathrm{O} 2$.

We can see in figure 4 the increase of the expression of the two caspases in a time-dependant manner with a maximum level at $18 \mathrm{~h}$ after treatment showing the entry of the cells in apoptosis [5]. 


\section{E. Gene expression profiling}

Gene expression profiling (GEP) is the measurement of the activity of thousands of genes at once, to create a global picture of cellular functions. The activity of a gene is represented by its expression, thus this technique shows whether a gene is active or not in a cell. These profiling can, for example, distinguish between cells that are actively dividing, or show how the cells react to a particular treatment. Drug treatment can modify the cell comportment, for instance dead induction, leading to modifications on the GEP with extinction of some genes and expression of new genes. GEP are obtained from cellular mRNA extracts. To highlight the genes modification of a cell treated by a molecule, mRNA are extract from treated cells and untreated cells. Then, the two GEP obtained from these two mRNA pool are compared. However, GEP is not the complete reflection of protein expression because all mRNA produced from a genome don't code for a protein. Moreover, many proteins are modified by the cell after their synthesis to be active and these modifications are not contained in the GEP. The information obtained from a comparison of GEP has to be confirmed by quantitative PCR based on a similar process but targeting some specific genes highlighted by the GEP measurements.

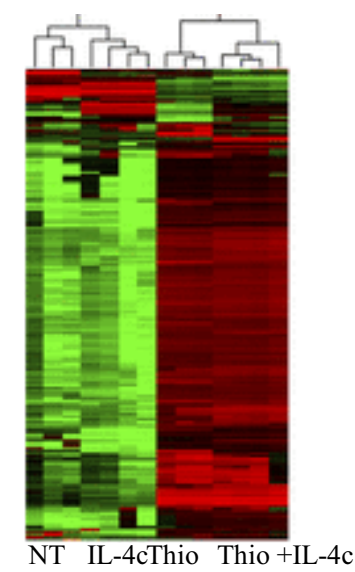

Fig. 5. Gene expression profiling of monocytes from untreated mice (NT) or mice treated with IL-4c alone or thioglycollate alone or Thio + IL-4c. (Three mice for each condition).

Figure 5 shows the GEP of monocytes taken from mice treated or not by 2 drugs: IL-4c and thioglycollate. The modification in the gene expression is represented by the color changes between the different conditions. We can see that treatment by thioglycollate change greatly the GEP when IL-4c has a little effect [6]. The comparison of these patterns gave to the authors the name of genes involved in the activation of the monocytes.

\section{F. Proteomics}

Proteomics is the large-scale study of proteins, their structure and functions. The proteome is the entire set of proteins, produced or modified by an organism or system. This varies with time and distinct requirements, or stresses, that a cell or organism undergoes. To obtain a proteome, total proteins are extracted from cells, purified, separated by electrophoresis and analyzed by mass spectrometry.

Proteome from treated cells can be obtained and compared to untreated cells. However, in this case, cells have to be cultivated in specific medium containing isotope of carbon, hydrogen or nitrogen.

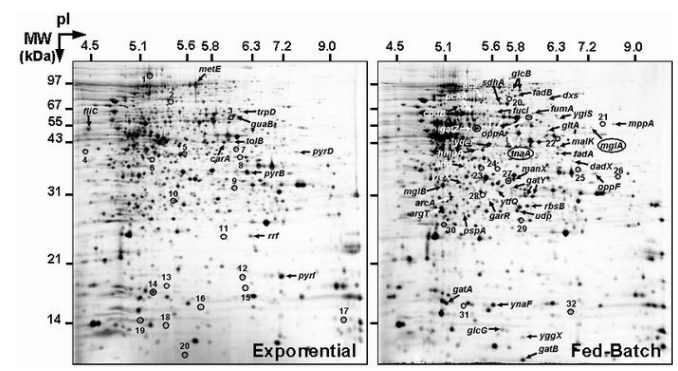

Fig. 6. Comparison of protein expression in Escherichia coli under exponential phase and fed-batch phase in glucose limited fed-batch fermentation.

Figure 6 shows proteomes of Escherichia coli cultivated in glucose excess (exponential) and in glucose limited (fed-batch). The comparison of the these two proteomes showed thirty protein spots (10 identified) significantly over-expressed in exponential phase, while 60 spots $(47$ identified) were over-expressed under fed-batch conditions [7]. Spots with circled gene names were not present in exponential phase gels. Spots can be extract and analyze by mass spectrometry to characterize proteins of interest.

\section{G. Metabolomics}

Metabolomics is the study of chemical processes involving metabolites. Metabolites are the intermediates and products of metabolism which is the machinery for cell functions (molecules synthesis, molecules degradations energy consumption.....). The metabolome represents the collection of all metabolites in a biological cell, tissue, organ or organism, which are the end products of cellular processes compared to the gene expression data which are the begin of the story. Metabolic profiling can give an instantaneous snapshot of the physiology of the cell.

The metabolome is obtained from biofluids or cellular extracts which are analyzed by Nuclear Magnetic Resonance (NMR) spectroscopy and/or mass spectrometry after separation by chromatography. 


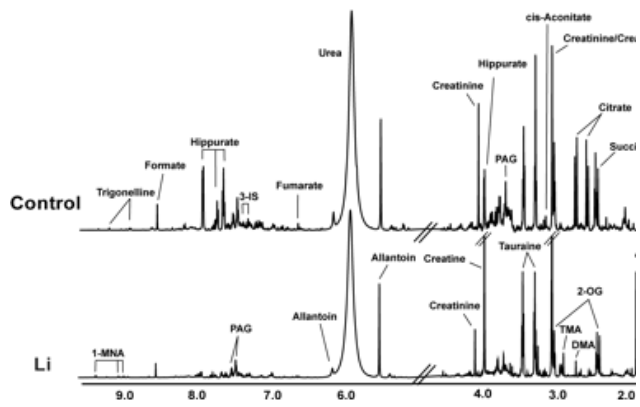

Fig. 7. Metabolome of urine from untreated and Lithiumtreated rats. Analysis by NMR spectroscopy.

Significant metabolic differences were observed in the study represented in figure 7 with the NMR spectra from the control and from Li-treated rats. Comparison of the urinary metabolite profiles between control and Li-treated rats revealed a significant increase in acetate and creatine but a decrease in hippurate in Li-treated rats [8].

\section{HFDS}

High Frequency Dielectric Spectroscopy is a biosensing approach which consists to apply microwaves (40 MHz up to $40 \mathrm{GHz}$ ) to biological samples and to measure transmitted waves. It presents the real advantages of being contact-less, non-invasive, non-ionizing and label-free because no marker is required to enable detection. Due to the microtechnologies evolution and their use in various fields, we can use with the HFDS miniature microwave circuits to perform biological sensing with dimensions close to cells. This method allows extracting the dielectric properties of various biological solutions with volume in the micro or nanoliter ranges. These properties are represented by the real $\left(\varepsilon^{\prime}\right)$ and the imaginary $\left(\varepsilon^{\prime}\right.$ ') parts of the complex permittivity of the sample studied. These two parameters are considered as providing a specific electrical signature of the biological sample.

As an example of HF signature, we choose to show the measure of human cell death obtained by the treatment with a detergent solution (saponin $0.02 \%$ ). The function of saponin is to produce holes in the plasma membrane leading to the permeabilization of the membrane then cell death.
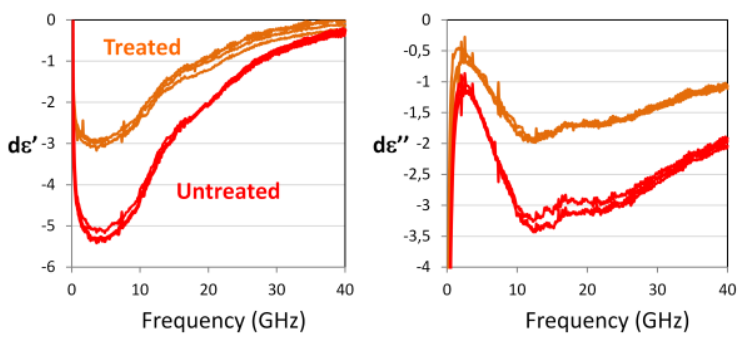

Fig. 8. HF dielectric spectra of untreated and treated lymphoma cells with a solution of saponin $(0.02 \%)$.
Figure 8 shows the loss of contrast when lymphoma cells are permeabilized by saponin exposure, reflected by the decrease of the permittivity ( $\varepsilon$ ' and $\varepsilon$ '). Compared to other biological techniques given above, no pretreatment or labeling of the sample was required to obtain these HF signatures [9].

\section{CONCLUSION}

Microwave biosensing at cellular level constitutes a promising approach for new biological and medical analyzing tools. HFDS generates a specific signature of cellular and molecular solutions being sensitive to the concentration and to the state of the cell, i.e. dead or alive. The advantages of miniaturizing, processing speed, small sample, no invasive treatment such as fixation, no labeling and the possible real time measurement open the door to the development of HFDS for non-invasive biological analysis.

\section{REFERENCES}

[1] Y. Ma, J. Jiang, L. Wang, H. Nie, W. Xia, J. Liu, W. Ying, “CD38 is a key enzyme for the survival of mouse microglial BV2 cells." Biochem. Biophys. Res. Commun. , vol. 418, no.4, pp. 714-719, Feb 2012.

[2] N. Hirahara, M. Fujioka, T. Edamatsu, A. Fujieda, F. Sekine, T. Wada, T. Tanaka, "Protein-bound polysaccharide-K (PSK) induces apoptosis and inhibits proliferation of promyelomonocytic Leukemia HL-60 cells"

Anticancer Res. , vol. 31, pp. 2733-2738, 2011.

[3] J. Zhao, X. Chen, W. Lin, G. Wu, Q. Zhuang, X. Zhong, Z. Hong, J. Pengh, "Total alkaloids of Rubus aleaefolius Poir inhibit hepatocellular carcinoma growth in vivo and in vitro via activation of mitochondrial-dependent apoptosis" Int. J. Oncol. , vol. 42, pp. 971-978, 2013.

[4] H. Towbin, T. Staehelin, J. Gordon, "Electrophoretic transfer of proteins from polyacrylamide gels to nitrocellulose sheets: procedure and some applications" Proc. Nat. Acad. Sci. USA, vol. 76, no. 9, pp. 4350-4354, 1979.

[5] Y. Hangping, T. Xiajing, S. Xueting, F. Lei, W. Nanping, Y. Ke "Parthenolide protects human lens epithelial cells from oxidative stress-induced apoptosis via inhibition of activation of caspase-3 and caspase-9" in Cell. Research, vol. 17, pp. 565-571, 2007.

[6] U. M. Gundra, N. M. Girgis, D. Ruckerl, S. Jenkins, L. N. Ward, Z. D. Kurtz, K. Wiens, M. Tang, U. Basu-Roy, A. Mansukhani, J. E. Allen, P'ng Loke, “Alternatively activated macrophages derived from monocytes and tissue macrophages are phenotypically and functionally distinct" Blood, vol. 123, pp. 20, 2014.

[7] B. Raman, M. P. Nandakumar, V. Muthuvijayan, M. R. Marten, "Proteome analysis to assess physiological changes in Escherichia coli grown under glucose-limited fed-batch conditions" Biotechn. Bioengineer., vol. 92, pp. 384-392, 2005.

[8] G.S. Hwang, J.Y. Yang, D.H. Ryu, T.H. Kwon, "Metabolic profiling of kidney and urine in rats with lithium-induced nephrogenic diabetes insipidus by ${ }^{1} \mathrm{H}-\mathrm{NMR}$-based metabonomics" Am. J. Physiol., vol. 298, pp. 461-470, 2010.

[9] F. Artis, D. Dubuc, J.J. Fournié, M. Poupot, K. Grenier, "Microwave dielectric spectroscopy of cell membrane permeabilization with saponin on human B lymphoma cells" IEEE International Microwave Symposium, 2014. 